\title{
Impact of oral simvastatin therapy on acute lung injury in mice during pneumococcal pneumonia
}

\author{
Angela R Boyd, Cecilia A Hinojosa, Perla J Rodriguez and Carlos J Orihuela*
}

\begin{abstract}
Background: Recent studies suggest that the reported protective effects of statins (HMG-CoA reductase inhibitors) against community-acquired pneumonia (CAP) and sepsis in humans may be due to confounders and a healthy user-effect. To directly test whether statins are protective against Streptococcus pneumoniae, the leading cause of CAP, we examined the impact of prolonged oral simvastatin therapy at physiologically relevant doses in a mouse model of pneumococcal pneumonia. BALB/c mice were placed on rodent chow containing $0 \mathrm{mg} / \mathrm{kg}$ (control), $12 \mathrm{mg} / \mathrm{kg}$ (low simvastatin diet [LSD]; corresponds to $1.0 \mathrm{mg} / \mathrm{kg} /$ day), or $120 \mathrm{mg} / \mathrm{kg}$ (high simvastatin diet [HSD]; corresponds to $10 \mathrm{mg} / \mathrm{kg} /$ day) simvastatin for four weeks, infected intratracheally with S. pneumoniae serotype 4 strain TIGR4, and sacrificed at 24, 36, or $42 \mathrm{~h}$ post-infection for assessment of lung histology, cytokine production, vascular leakage and edema, bacterial burden and bloodstream dissemination. Some mice received ampicillin at 12-h intervals beginning at $48 \mathrm{~h}$ post-infection and were monitored for survival. Immunoblots of homogenized lung samples was used to assess ICAM-1 production.

Results: Mice receiving HSD had reduced lung consolidation characterized by less macrophage and neutrophil infiltration and a significant reduction in the chemokines MCP-1 $(P=0.03)$ and KC $(P=0.02)$ and ICAM-1 in the lungs compared to control mice. HSD mice also had significantly lower bacterial titers in the blood at $36(P=0.007)$ and $42(P=0.03)$ hours post-infection versus controls. LSD had a more modest effect against $S$. pneumoniae but also resulted in reduced bacterial titers in the lungs and blood of mice after $42 \mathrm{~h}$ and a reduced number of infiltrated neutrophils. Neither LSD nor HSD mice had reduced mortality in a pneumonia model where mice received ampicillin $48 \mathrm{~h}$ after challenge.

Conclusions: Prolonged oral simvastatin therapy had a strong dose-dependent effect on protection against S. pneumoniae as evidenced by reduced neutrophil infiltration, maintenance of vascular integrity, and lowered chemokine production in the lungs of mice on HSD. Statin therapy also protected through reduced bacterial burden in the lungs. Despite these protective correlates, mortality in the simvastatin-receiving cohorts was equivalent to controls. Thus, oral simvastatin at physiologically relevant doses only modestly protects against pneumococcal pneumonia.
\end{abstract}

\section{Background}

Statins, or 3-hydroxy-3 methylglutaryl coenzyme A (HMG$\mathrm{CoA}$ ) reductase inhibitors, are prescribed to treat elevated levels of cholesterol and cardiovascular disease. As such they are among the most commonly prescribed drugs in the United States and worldwide. While statins can reduce plasma cholesterol by as much as $30-55 \%$, statins also have potent anti-inflammatory and immunomodulatory

\footnotetext{
* Correspondence: orihuela@uthscsa.edu
Department of Microbiology and Immunology, The University of Texas

* Correspondence: orihuela@uthscsa.edu
Department of Microbiology and Immunology, The University of Texas Health Science Center at San Antonio, 7703 Floyd Curl Drive, San Antonio, TX 78229-3900, USA
}

(c) 2012 Boyd et al.; licensee BioMed Central Ltd. This is an Open Access article distributed under the terms of the Creative Commons Attribution License (http://creativecommons.org/licenses/by/2.0), which permits unrestricted use, distribution, and reproduction in any medium, provided the original work is properly cited.

properties that may be beneficial against certain infectious diseases in particular community-acquired pneumonia (CAP) [1].

In 2004, a prospective observational cohort study of individuals admitted to hospital for bacterial infection found that those taking statins had reduced incidence of sepsis and intensive care unit (ICU) admission [2]. Retrospective studies by Mortensen et al., determined that prior statin use was associated with reduced 30-day mortality in patients admitted with CAP or sepsis [3,4]. Importantly, statin use was shown to reduce the risk of CAP in patients with diabetes, an established risk factor 
for CAP [5]. To date, greater than 20 independent studies have reported on the effects of statins on CAP and sepsis with a recent meta-analysis by Janda et al. reporting a strong beneficial effect against pneumonia- and sepsis-related mortality [6].

Importantly, not all studies identified a protective effect for statins against CAP [7-9]. For example a recent 2011 study by Yende et al., which accounted for healthy user effect and indication bias using propensity analysis, found no evidence for a protective effect in 1895 subjects hospitalized for CAP across 28 U.S. hospitals [9]. Likewise, in a study of 3415 individuals admitted to a hospital with pneumonia, Majundar et al. found that prior statin use had no effect on mortality or need for admission to an ICU [8]. Finally, de Saint Martin et al. found that statins users had higher ICU admission rates than non-users, albeit no differences in length of hospital stay or mortality were observed [7]. The authors of these studies suggest that the protective effects reported for statins may be due to confounders, a healthy user effect, and/or indication bias. As results from randomized control trials are not yet published, direct evidence of whether statins confer protection against CAP remains controversial.

Studies investigating the effects of statins on bacterial infections using laboratory animals have yielded conflicting results and added to the uncertainty. In a mouse model of Klebsiella pneumoniae pneumonia, lovastatin administration resulted in increased bacterial outgrowth that the authors attributed to reduced neutrophil accumulation within the lungs and defects in neutrophildependent intracellular killing [10]. For Staphylococcus aureus, high-dose statin therapy was shown to enhance the production of antimicrobial extracellular DNA traps by phagocytes within the lungs of mice and to protect against disseminated infection $[11,12]$. We have recently shown that short-term simvastatin therapy reduced the severity of pneumococcal disease in mice with sickle-cell disease but had no protective effect on young wild type mice [13]. Statin-mediated protection in the sickle-cell animals was due to: 1 ) reduced levels of Platelet-activating factor receptor, a host-protein that Streptococcus pneumoniae co-opts to adhere and invade host cells, and 2) reduced cytotoxicity of pneumolysin, a cholesterol dependent pore-forming toxin produced by $S$. pneumoniae. Of note, for all the animal studies described above, statins were either administered through a non-oral route, on a short-term basis, or at doses that far exceed what would normally be administered to humans for cardiovascular disease. Thus the mechanisms that might protect humans against pneumonia following oral statin therapy remain in question.

Given the large number of individuals at risk for pneumonia, it is important to determine whether prolonged oral statin therapy confers protection against pneumonia and if so the mechanisms that are responsible. For this reason we examined the effect of 4-week entericdelivered simvastatin on the progression and severity of pneumococcal pneumonia in mice. Our findings indicate that simvastatin therapy reduced bacterial burden, decreased neutrophil influx, and diminished lung damage, but did not affect overall mortality. These studies provide experimental evidence supporting the notion that prophylactic statin therapy can exert protective benefits against CAP in humans; however these effects are modest in mice at the maximum recommended dose of simvastatin for humans.

\section{Materials and methods}

\section{Mice and simvastatin diet}

All experiments were performed in compliance with approved Institutional Animal Care and Use Committee protocols. Female 12-16 week old BALB/c mice were purchased from The Jackson Laboratory (Bar Harbor, MA). Rodent chow containing simvastatin (Sigma, St. Louis $\mathrm{MO}$ ) at $0 \mathrm{mg} / \mathrm{kg}$ (control), $12 \mathrm{mg} / \mathrm{kg}$ (low simvastatin diet [LSD]), or $120 \mathrm{mg} / \mathrm{kg}$ (high simvastatin diet [HSD]) was prepared by Purina TestDiet (Richmond, IN) and fed ad libitum for $\geq 4$ weeks. For a 25-30 g mouse consuming 2-2.5 g of chow per day these diets correspond to 1.0 and $10 \mathrm{mg} / \mathrm{kg} /$ day of simvastatin, respectively. Previous studies have confirmed a therapeutic effect for LSD and HSD by testing for a reduction in serum cholesterol [14].

\section{Assessment of disease severity}

S. pneumoniae serotype 4, strain TIGR4 was grown in Todd Hewitt Broth at $37^{\circ} \mathrm{C}$ in $5 \% \mathrm{CO}_{2}$ [15]. Animals were anesthetized with vaporized isoflurane and $10^{5} \mathrm{cfu}$ in $100 \mu \mathrm{l}$ phosphate-buffered saline (PBS) was delivered intratracheally by forced inhalation [16]. Mice were euthanized and bacterial burden in the lungs was assessed per gram of homogenized tissue. Alternatively, bacteremia and mortality was assessed over 7 days [17]. In intervention experiments, beginning at $48 \mathrm{~h}$ post-challenge, mice were administered ampicillin $(80 \mathrm{mg} / \mathrm{kg})$ at $12 \mathrm{~h}$ intervals. Lungs sections $(5 \mu \mathrm{m})$ were stained with $\mathrm{He}$ matoxylin and Eosin (H\&E) and scored in a blind manner based on lung consolidation, evidence of hemorrhage, and extent of cellular infiltration.

\section{Bronchoalveolar lavage (BAL)}

Mice were euthanized by $\mathrm{CO}_{2}$ asphyxiation. Following surgical visualization of the trachea, BAL was performed by insertion of a 0.18 gauge angiocatheter and flushing of the lungs with $0.5 \mathrm{ml}$ ice-cold PBS until a total volume of $3 \mathrm{ml}$ was obtained. BAL fluid was strained $(40-\mu \mathrm{M})$ and centrifuged. The cellular fraction was suspended in 
$1 \mathrm{ml}$ PBS and total cell counts were determined using a hemocytometer. Differential cell counts were done following cytospin and staining with a Diff-Quick Staining Kit (IMEB Inc.); >300 cells were counted in three separate fields for each mouse.

\begin{abstract}
Albumin and cytokine analysis
Vascular leakage in BAL fluid was assessed using a mouse albumin ELISA Quantitation Set (Bethyl Laboratories, Inc., Montgomery, TX). Levels of Tumor Necrosis Factor (TNF) $\alpha$, Interleukin (IL)-6, IL-10, IL-12, Monocyte chemoattractant protein (MCP)-1, and Interferon $(\mathrm{IFN}) \gamma$ in BAL fluid and serum samples were performed using a Mouse Inflammatory Cytometric Bead Array (BD Biosciences). Concentrations of $\mathrm{KC}$ were determined using a DuoSET Mouse CXCL1/KC ELISA kit from R\&D Systems (Minneapolis, MN).
\end{abstract}

\section{Determination of ICAM-1 protein levels in the lungs}

Lungs were homogenized in RIPA buffer containing a protease inhibitor cocktail (Sigma). Separation of protein by SDS-PAGE, transfer to nitrocellulose membrane, and detection was performed using standard immunoblot methods. Goat polyclonal antibody to ICAM-1 (Santa Cruz Biotechnology) was used for detection. Relative protein levels were determined by densitometric analysis of Western blot bands using a Molecular Imager Gel Doc XR System (BioRad, Hercules, CA). To ensure that equal amount of protein had been probed, and to permit normalization of ICAM-1 across samples, membranes were stripped and the amount of actin determined using rabbit anti-actin antibodies (Bethyl Laboratories, Inc., Montgomery, TX).

\section{Statistical analysis}

For comparisons between cohorts either a One-way ANOVA or two-tailed Student's $t$ test was used as indicated. $P$ values $<0.05$ were considered significant. For survival analyses a Kaplan-Meier Log Rank Survival Test was used.

\section{Results}

Oral statin prophylaxis decreases the severity of pneumococcal pneumonia in mice

To determine the effect of simvastatin prophylaxis on disease severity we first assessed bacterial burden during pneumonia. Pneumococcal titers in the lungs collected at $24 \mathrm{~h}$ post-infection (hpi) did not significantly differ between the simvastatin fed and control cohorts (Figure 1); although bacterial titers in the lungs of mice on HSD had a trend towards reduced bacterial load $(P=0.08)$. At $42 \mathrm{hpi}$, mice on the control diet had approximately $50-(P=0.02)$ and 100 -fold $(P=0.002)$ more bacteria in their lungs than mice on LSD and HSD, respectively. In agreement with this reduced bacterial load, histological analysis of lung sections demonstrated decreased lung damage with less evidence of lung consolidation, edema, and hemorrhage in the HSD mice versus controls (Figure 2A). Mice receiving LSD had no discernible difference in lung damage versus controls. Analysis of BAL fluid for evidence of vascular leakage demonstrated that mice on HSD had reduced albumin in their lungs 24 hpi (Figure 2B). No differences in albumin levels were found between mice receiving the LSD versus the control diet or in baseline levels of albumin prior to infection. Thus, HSD seemed to protect vascular integrity during infection.

We subsequently examined the impact of oral simvastatin therapy on development of bacteremia. Following intratracheal challenge at $24 \mathrm{hpi}$, bacterial titers in the blood were not significantly different among all three groups tested; although mice receiving HSD had lower median titers compared to mice on the control diet $(P=0.12)$ (Figure 3$)$. Between 24 and $36 \mathrm{~h}$, pneumococcal titers in the blood increased at a similar rate for all mice, nonetheless mice on HSD had significantly fewer pneumococci in their blood compared to control mice $(P=0.007)$. After $36 \mathrm{~h}$, mice receiving the control diet continued to experience bacterial replication whereas those on a simvastatin diet maintained or began to clear bacteria from the blood. At $42 \mathrm{hpi}$, mice on the HSD

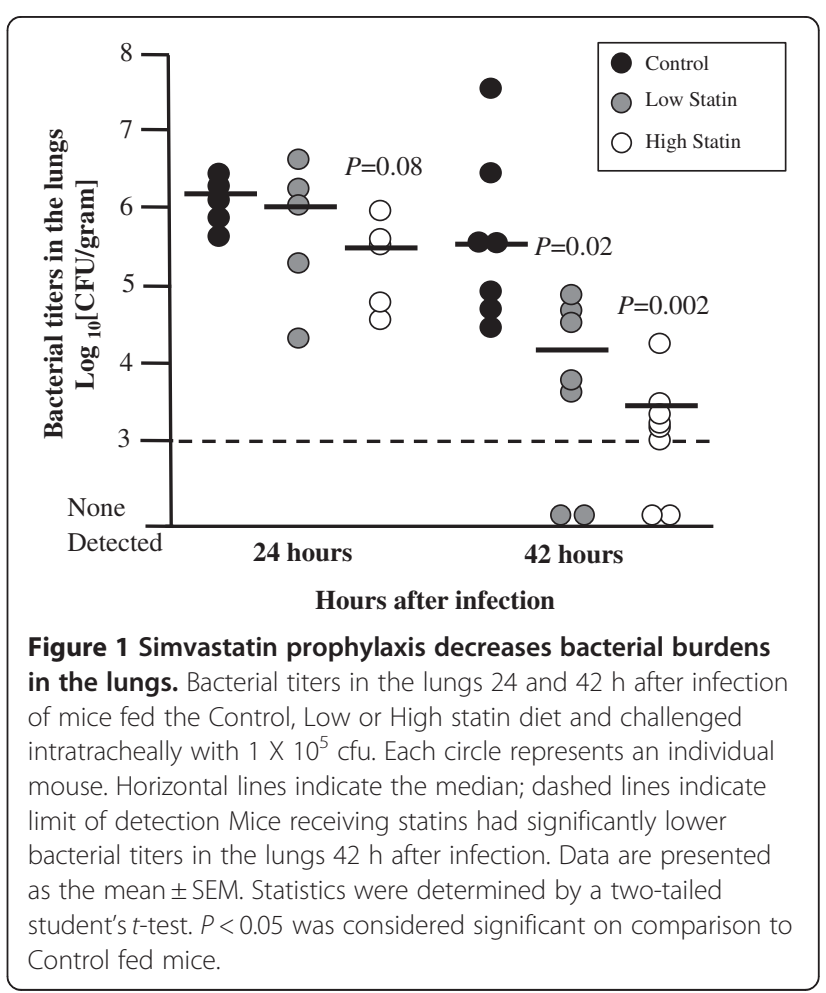



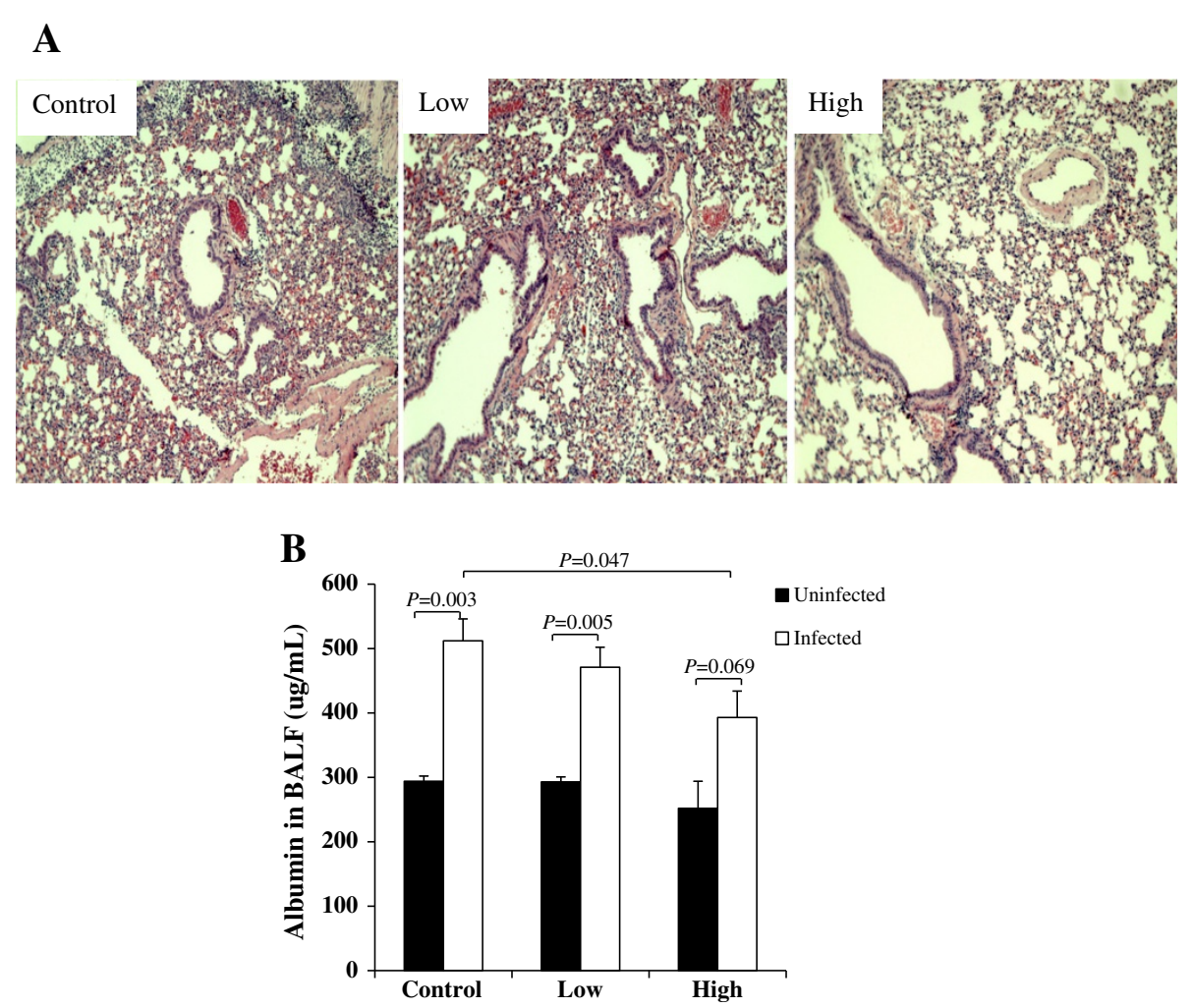

Figure 2 Simvastatin prophylaxis decreases histopathology and vascular leakage. A) Representative micrographs of Hematoxylin- and Eosin-stained lung sections from mice $42 \mathrm{~h}$ after infection. Note that the high statin fed mice exhibit reduced cellularity and vascular hemorrhage. Original magnification, 10X. B) Vascular integrity was determined by assessing the amount of albumin present in the BAL fluid by ELISA prior to and following infection ( $n=3 /$ group for uninfected and $n=6 /$ group for infected mice). Data are presented as the mean $\pm S E M$. Statistics were determined by a two-tailed student's $t$-test. $P<0.05$ was considered significant in comparison to Control fed mice.

continued to have significantly less bacterial titers in the blood compared to control fed mice $(P=0.03)$.

\section{High-dose simvastatin reduces chemokine production in the lungs}

Statins have been reported to reduce cytokine production following LPS stimulation of monocytes and decrease lung inflammation following instillation of LPS in healthy human volunteers $[18,19]$. Thus we investigated the effect of simvastatin therapy on the local and systemic production of cytokines and chemokines during pneumococcal pneumonia. At $24 \mathrm{hpi}$, before bacterial titers in the lungs were significantly different, no differences were observed for TNF $\alpha$, IL-6, IL-10, IL-12, MCP$1, \mathrm{KC}$ and IFNY in the BAL fluid or serum of mice on LSD versus controls (Figure 4A, B). In contrast, mice on HSD had significant reductions in MCP-1 $(P=0.03)$ and KC $(P=0.02)$ in the BAL fluid but not serum. No differences were observed for all other cytokines or chemokines in the BALF or in the serum of HSD mice. Uninfected mice on control, LSD and HSD had unaltered low levels of cytokines and chemokines present in the BAL fluid and serum prior to infection (data not shown).

\section{Statins impact neutrophil influx and ICAM-1 expression}

Statins have been reported to reduce neutrophil influx into the lungs following instillation of LPS and during $K$. pneumoniae infection [10]. We therefore assessed whether oral simvastatin also attenuated cellular influx into the lungs during pneumococcal pneumonia. Total cell counts using BAL fluid collected at 24 hpi demonstrated that mice receiving HSD had significantly less cellular infiltration compared to control mice $(P<0.001)$ (Figure 5A). Notably, infected HSD mice had only a nominal increase in cellular infiltrates $(P=0.07$ versus controls) versus the mock-infected controls, confirming that high-dose statins indeed reduced leukocyte influx. In contrast, mice on control and LSD had a robust and significant cellular response versus uninfected controls (Control, $P<0.001$; LSD, $P=0.02$ ).

Although during infection the absolute numbers of leukocytes in the BAL did not differ between mice on LSD and control diet, those receiving LSD had significantly less neutrophils in the BAL compared to control 


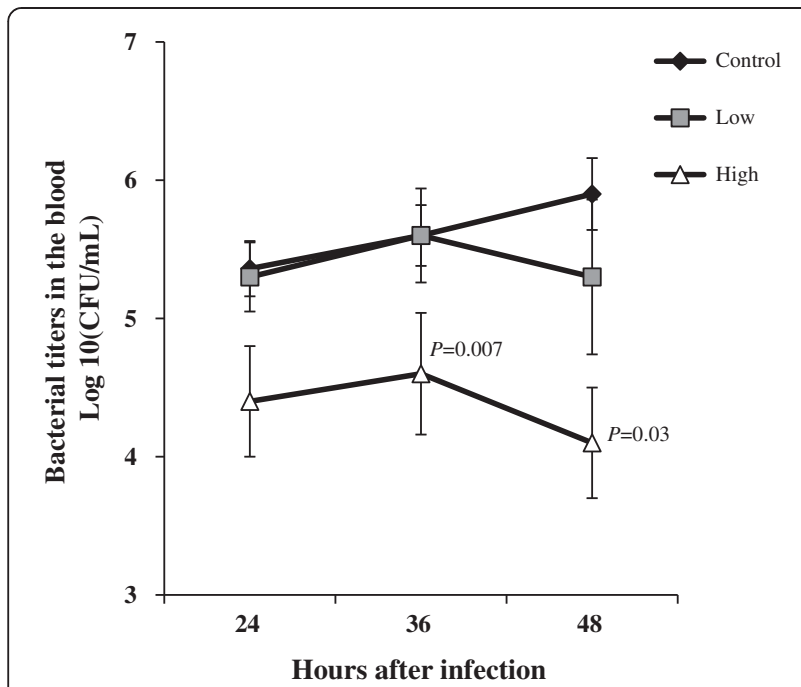

Figure 3 Mice on simvastatin prophylaxis show enhanced protection from bacteremia. Bacterial titers in the blood of challenged mice 24, 36 and $42 \mathrm{~h}$ after infection. Mice on Control $(n=11)$, Low $(n=11)$ or High $(n=12)$ diet were challenged intratracheally with $1 \times 10^{5} \mathrm{cfu}$. Mice receiving statins had significantly fewer bacteria in the blood. Data are presented as the mean \pm SEM. Statistics were determined by a two-tailed student's t-test. $P<0.05$ was considered significant.

fed mice $(P=0.03)$ (Figure $5 C)$. Mice receiving HSD also had a significant reduction in the number of infiltrating neutrophils $(P<0.001)$. Differences in neutrophil numbers were dose-dependent with those on the LSD and HSD at approximately $75 \%$ and $25 \%$ of the levels observed for the control diet, respectively. Importantly, a less dramatic effect was observed for macrophages/ monocytes. Only infected mice on HSD had a significant reduction in numbers versus their infected controls $(P=0.01)$ (Figure 5B).

Statins have been found to decrease the up regulation of adhesion molecules on endothelial cells in several models of inflammation [20-22]. Because we observed a dose-dependent reduction in neutrophil influx, yet only mice on the HSD had lower production of the neutrophil chemoattractant $\mathrm{KC}$, we went on to assess whether statins were reducing neutrophil infiltration by modulating the upregulation of adhesion molecules. In agreement with the observed reduction in neutrophils influx, mice receiving statins had a strong dose-dependent reduction in the protein levels of ICAM-1 present in the lungs prior to infection with S. pneumoniae (Control versus LSD, $P=0.04$; Control versus $H S D, P=0.004$ ) (Figure 6A). Whereas at $24 \mathrm{hpi}$, only mice on the HSD continued to have decreased protein levels of ICAM-1 in the lungs $(P=0.02)$ (Figure $6 \mathrm{~B})$. Taken together these findings suggest that statins exert a dose-dependent effect to reduce neutrophil infiltration during pneumococcal pneumonia by reducing neutrophil chemotaxis
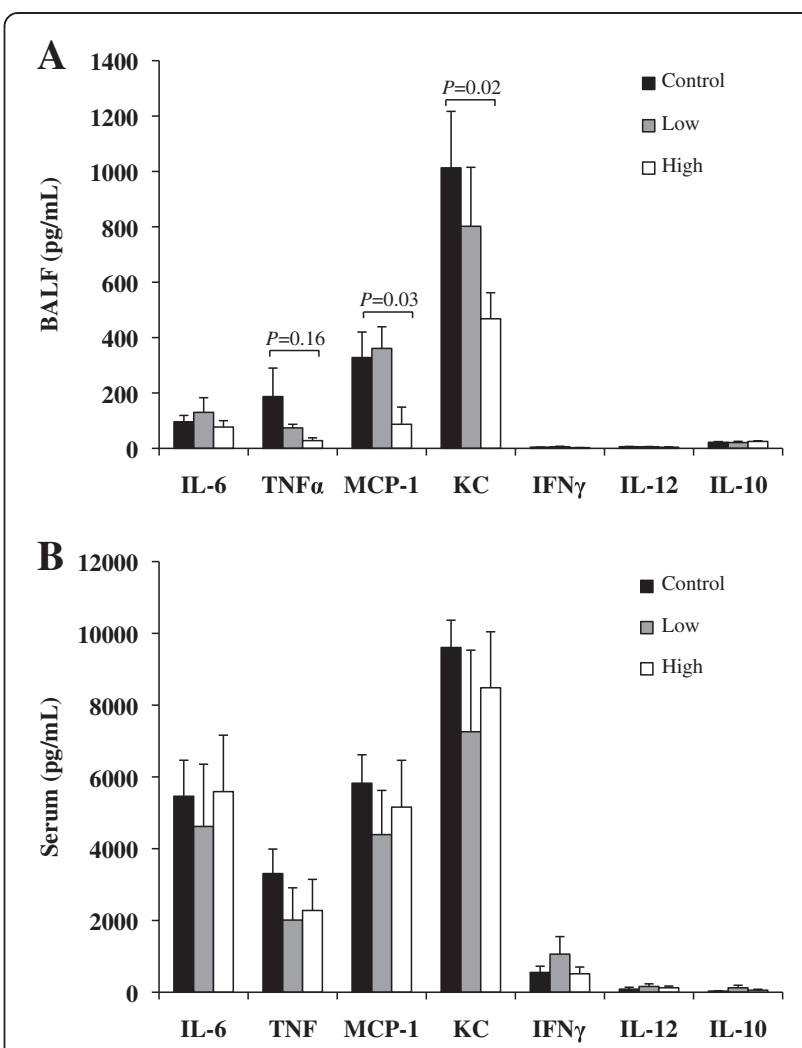

Figure 4 Statins preferentially decrease chemokine production in the lungs without reducing proinflammatory mediators during early pneumococcal pneumonia. Control, Low, and High statin mice were challenged intratracheally with $1 \times 10^{5} \mathrm{cfu}$ and sacrificed $24 \mathrm{~h}$ after infection. Collected $\mathbf{A}$ ) bronchoalveolar lavage fluid and B) serum were assayed for pro-inflammatory cytokine and chemokine production by a mouse inflammatory cytometric bead array or ELISA ( $n=12$ /group). No statistically significant differences in cytokine production were observed, while the chemokines MCP-1 and $\mathrm{KC}$ were significantly decreased in mice receiving the high statin diet compared to control. Data are presented as the mean \pm SEM. Statistics were determined by a two-tailed student's t-test. $P<0.05$ was considered significant in comparison to Control fed mice.

and transcytosis without suppressing pro-inflammatory mediators required to enhance antibacterial defense mechanism.

Surivival of infected mice on statins Finally, we sought to directly test if prophylactic statin therapy improved disease outcomes in a clinically relevant infection model. Since individuals with CAP receive antimicrobials, we tested for survival of mice in a model where beginning at $48 \mathrm{hpi}$ mice received ampicillin at $12 \mathrm{~h}$ intervals. Despite the protective effects observed above, mice on LSD or HSD had equivalent survival over time as controls (Figure 7). Thus, the overall protective effects of statins were modest and may not necessarily impact disease outcomes in humans. 

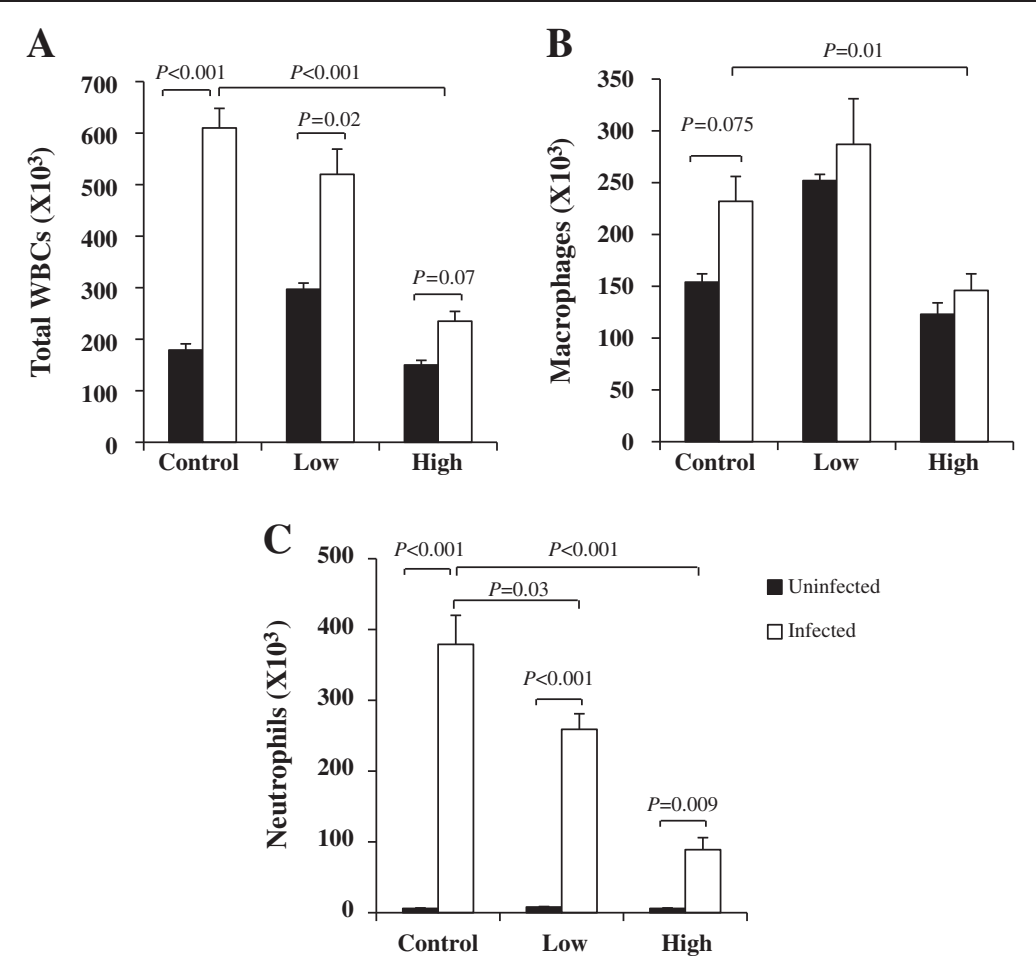

Figure 5 Statins decrease leukocyte infiltration into the lungs. A) Total cell counts obtained by bronchoalveolar lavage (BAL) $24 \mathrm{~h}$ after intratracheal infection with $1 \times 10^{5}$ cfu were determined by visual counting using a hemocytometer ( $\left.n=6 / g r o u p\right)$. Differential cell counts of cytospins prepared from the same BAL demonstrating B) lower monocytes/macrophages in mice receiving the high statin diet and C) a dosedependent reduction in neutrophil influx $24 \mathrm{~h}$ after infection. Data are presented as the mean \pm SEM. Statistics were determined by a two-tailed student's t-test. $P<0.05$ was considered significant in comparison to Control fed mice.

\section{Discussion}

Numerous studies, including recent meta-analyses, have reported an association between prior statin use and improved outcomes following CAP and sepsis [6,23]. Conversely, a recent study by Yende et al., in which the authors accounted for healthy user effect and indication bias using propensity analysis, found no evidence for a protective effect of statins on clinical outcomes [9]. Experiments with laboratory animals can directly test whether statins are protective against infectious diseases. Unfortunately, studies thus far have been flawed by either short-duration of statin therapy, the administration of too high levels of statins, and non-enteric delivery of the drug. Thus, at the onset of our study, it was unclear whether prolonged simvastatin therapy, delivered enterically for 4 weeks, and at a dose taken by humans for high cholesterol (LSD; $1.0 \mathrm{mg} / \mathrm{kg} /$ day) would be protective against $S$. pneumoniae. Most evident from our studies was the strong dose-dependent effect of simvastatin on examined parameters; for LSD we observed only reduced bacterial titers in the lungs at 42 hpi and intermediate reductions in neutrophil influx and ICAM-1 expression. In contrast, mice receiving HSD (i.e. $10 \mathrm{mg} / \mathrm{kg} /$ day; 10X maximum recommended human dose) had significantly reduced bacterial titers in the lungs and blood, less lung damage, and diminished cytokine production and neutrophil recruitment. Therefore, the dose of statin received by participating individuals in human trials for statins should be a key consideration.

Excessive cellular infiltrates is a common complication of CAP. Likewise, ours is not the first study to suggest that statins attenuate neutrophil influx or edema during infection or injury [12,19,24-26]; with a similar effect for lovastatin $(10 \mathrm{mg} / \mathrm{kg}$ administered intraperitoneal 20,12 , and $0.5 \mathrm{~h}$ preceding exposure) reported by Fessler et al. during K. pneumoniae infection [10]. Based on our findings, reduced neutrophil infiltration can now be attributed to reduced chemokine production (e.g. MCP-1 and $\mathrm{KC})$ as well as a reduction in ICAM-1 levels that together reduces the entry of circulating neutrophils and macrophages into the lungs. Notably, and despite considerable lung protection observed in HSD mice, we found no significant differences in IL-6 or TNF $\alpha$ levels, the two pro-inflammatory cytokines most often correlated with severity of CAP [27]. Thus, in our study simvastatin did not prevent a "cytokine storm" and instead acted through decreased cellular infiltration and vascular leakage. This cautions against using IL-6 and TNF $\alpha$ as correlates of protection in human trials. Of note, this contrasts findings by Ando et al., where pretreatment of 

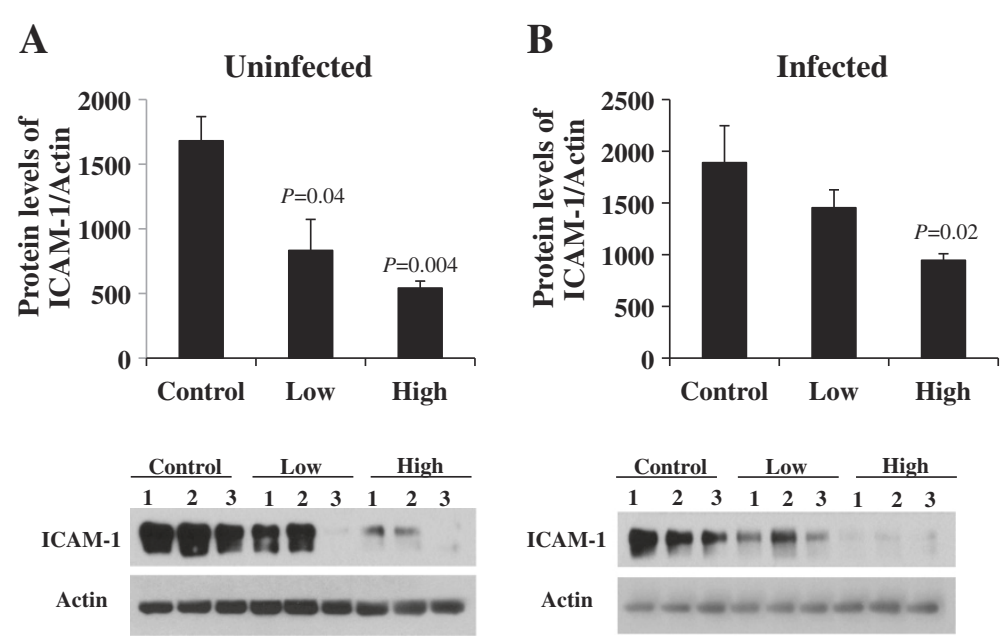

Figure 6 Statins decrease ICAM-1 protein expression prior to and following infection with S. pneumoniae. Lungs from mice on Control, Low, and High statin diet ( $n=6 /$ group) were examined for protein expression of ICAM-1 prior to and $24 \mathrm{~h}$ following intratracheally infection with $1 \times 10^{5}$ cfu by western blot analysis of whole lung protein lysates ( $n=3 /$ group for uninfected and $n=6 /$ group for infected mice). Mice receiving statins had significantly less ICAM-1 protein levels present in the lungs both $\mathbf{A}$ ) prior to and $\mathbf{B}$ ) following infection. Data are presented as the mean \pm SEM. Statistics were determined by a two-tailed student's t-test. $P<0.05$ was considered significant in comparison to Control fed mice.

the mice with cerivastatin $(20 \mathrm{mg} / \mathrm{kg}$ i.p. 12 and $1 \mathrm{~h}$ before challenge) reduced serum levels of TNF $\alpha$ and IL-1 $\beta$ following LPS administration ( $15 \mathrm{mg} / \mathrm{kg}$ i.p.). This difference may be due to the use of different statins, distinct routes of drug administration and bacterial challenge,

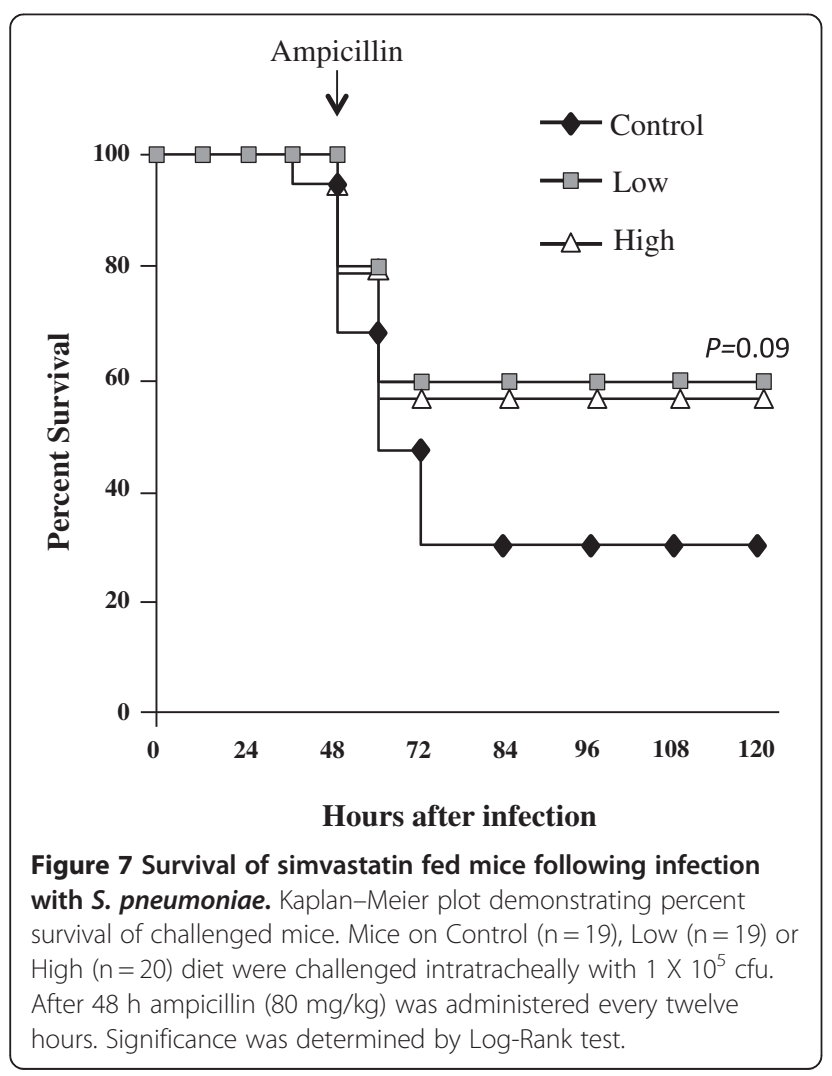

our use of a lower dose, and because we examined the response to a Gram-positive bacteria [26]. The latter applies to all the aforementioned animal studies as well. It is worth noting that statins have a well-documented anti-inflammatory effect that is independent of infection. For example, Müller et al., found that simvastatin treatment limited pulmonary endothelial injury, attenuated pulmonary hyperpermeability, prevented the recruitment of leukocytes to the lung, reduced pulmonary cytokine levels and improved oxygenation in mechanically ventilated mice [28]. Thus our findings for HSD are consistent with those of Müller et al.

During pneumonia, neutrophils are the primary effector cell responsible for clearance of extracellular bacteria. It was therefore paradoxical that reduced neutrophil infiltration was observed in HSD mice simultaneously to decreased bacterial burden in their lungs. In our hands, simvastatin does not have antibacterial effects in vitro on S. pneumoniae at in vivo concentrations $[13,29]$. Yet, Jerwood et al. have shown that simvastatin has considerable antimicrobial properties against Staphylococcus aureus [30]. Thus we cannot directly rule out killing by simvastatin in vivo. Possible reasons for the reduction in bacterial burden also include lowered PAFr expression in the lungs that would decrease bacterial adhesion and/or enhanced killing ability by resident alveolar macrophages due to enhanced resistance to the cholesterol-dependent toxin pneumolysin [13]. Although not tested in our study, high dose statins has also been reported to increase killing of $S$. aureus and S. pneumoniae by enhancing the formation of phagocyte extracellular traps in mice fed pulverized rodent chow 
supplemented with $500 \mathrm{mg} / \mathrm{kg}$ simvastatin [11]. For S. pneumoniae, killing by extracellular traps remains controversial as other investigators have shown that $S$. pneumoniae is able to resist neutrophil extracellular traps (NETs) due to the presence of a surface localized endonuclease that degrades the DNA scaffold of NETs $[31,32]$.

Importantly, the discrepancy in disease severity in mice for $S$. pneumoniae with simvastatin and for $K$. pneumoniae with lovastatin, as reported by Fessler et al. [10], raises the possibility that statins facilitate differential outcomes depending on the infectious agent. Neutrophils are a primary mediator of lung injury during pneumonia and a study with neutropenic mice infected with S. pneumoniae demonstrated less lung injury and improved survival $[33,34]$. Our findings are consistent with these previous publications. In addition to the differences in the class and delivery of statins used between our study and that of Fessler et al., another important consideration is that Gram-negative bacteria do not produce cholesterol-dependent cytolysins, such as pneumolysin. Statins might preferentially protect against Gram-positive bacteria. Such species-specific effects would have considerable implications regarding the utility of statins as a prophylactic drug within a hospital setting where the etiological cause of pneumonia is more frequently Gram-negative bacteria [35]. This further suggests that statin studies consider the etiological agent responsible for CAP.

In our clinical intervention model we observed no protection for challenged LSD or HSD mice as measured by survival. Worth consideration is the possibility that improved survival might have been observed if the ampicillin therapy was begun earlier. This notion is supported by the reduced bacterial titers in the blood of mice on LSD and HSD at $42 \mathrm{~h}$ hpi. Nonetheless, this observation suggests that the protective effects of statins are overall modest; even when a high dose of simvastatin is administered. One important caveat is that rodents metabolize drugs at different rates than humans and so the protective effect of statins may be more pronounced in humans at lower doses. Nonetheless our findings strongly suggest that individuals taking lower levels of statins would have reduced-protection against CAP versus those on higher doses. Finally, these observations highlight the complexity of the clinical question and indicate that human trials on statins for CAP should have multiple correlates of protection.

\section{Conclusion}

In summary, this study demonstrates that oral statin therapy may protect against pneumococcal pneumonia by increasing bacterial clearance, reducing excessive neutrophil infiltration, and decreasing vascular permeability.
Importantly, a strong dose-dependent effect was observed for simvastatin with minimal effects on mice administered the maximum recommended human dose (i.e. LSD) and no differences in overall survival observed for mice on HSD. Our observations help to explain why some human studies fail to find a protective effect as multiple correlates of protection are required for testing and multiple variables most likely affect outcomes including statin dose, etiological cause of CAP, and severity of CAP at time of admission.

\section{Author contributions}

ARB, $\mathrm{CH}$, and PJR performed the experiments and generated the data. ARB and $\mathrm{CJO}$ contributed to the conception and design of the experiments performed as well as the writing of the manuscript. All authors read and approved the final manuscript.

\section{Acknowledgements}

CJO is supported by NIH grants AG033274 and HL108054.

Received: 21 November 2011 Accepted: 3 May 2012

Published: 15 May 2012

\section{References}

1. Corrales-Medina VF, Musher DM: Immunomodulatory agents in the treatment of community-acquired pneumonia: a systematic review. $J$ Infect 2011, 63(3):187-199.

2. Almog Y, Shefer A, Novack V, Maimon N, Barski L, Eizinger M, Friger M, Zeller L, Danon A: Prior statin therapy is associated with a decreased rate of severe sepsis. Circulation 2004, 110(7):880-885.

3. Mortensen EM, Restrepo Ml, Anzueto A, Pugh J: The effect of prior statin use on 30-day mortality for patients hospitalized with communityacquired pneumonia. Respir Res 2005, 6:82.

4. Mortensen EM, Restrepo MI, Copeland LA, Pugh JA, Anzueto A, Cornell JE, Pugh MJ: Impact of previous statin and angiotensin II receptor blocker use on mortality in patients hospitalized with sepsis. Pharmacotherapy 2007, 27(12):1619-1626.

5. van de Garde EM, Hak E, Souverein PC, Hoes AW: van den Bosch JM. Leufkens HG: Statin therapy and reduced risk of pneumonia in patients with diabetes. Thorax; 2006.

6. Janda S, Young A, Fitzgerald JM, Etminan M, Swiston J: The effect of statins on mortality from severe infections and sepsis: a systematic review and meta-analysis. J Crit Care 2010, 25(4):e657-622. 656.

7. De Saint Martin L, Tande D, Goetghebeur D, Pan-Lamande M, Segalen Y, Pasquier E: Statin use does not affect the outcome of acute infection: a prospective cohort study. Presse Med 2010, 39(3):e52-57.

8. Majumdar SR, McAlister FA, Eurich DT, Padwal RS, Marrie TJ: Statins and outcomes in patients admitted to hospital with community acquired pneumonia: population based prospective cohort study. BMJ 2006, 333 (7576):999.

9. Yende S, Milbrandt EB, Kellum JA, Kong L, Delude RL, Weissfeld LA, Angus $D C$ : Understanding the potential role of statins in pneumonia and sepsis. Crit Care Med 2011, 39(8):1871-1878.

10. Fessler MB, Young SK, Jeyaseelan S, Lieber JG, Arndt PG, Nick JA, Worthen GS: A role for hydroxy-methylglutaryl coenzyme a reductase in pulmonary inflammation and host defense. Am J Respir Crit Care Med 2005, 171(6):606-615.

11. Chow OA, von Kockritz-Blickwede M, Bright AT, Hensler ME, Zinkernagel AS, Cogen AL, Gallo RL, Monestier M, Wang Y, Glass CK, et al: Statins enhance formation of phagocyte extracellular traps. Cell Host Microbe 2010, 8(5):445-454.

12. McDowell SA, Ma Y: Kusano R. Akinbi HT: Simvastatin is Protective During Staphylococcus aureus Pneumonia. Curr Pharm Biotechnol; 2011.

13. Rosch JW, Boyd AR, Hinojosa E, Pestina T, Hu Y, Persons DA, Orihuela CJ, Tuomanen El: Statins protect against fulminant pneumococcal infection and cytolysin toxicity in a mouse model of sickle cell disease. J Clin Invest 2010, 120(2):627-635. 
14. Miller RA, Harrison DE, Astle CM, Baur JA, Boyd AR, de Cabo R, Fernandez E, Flurkey K, Javors MA, Nelson JF, et al: Rapamycin, but not resveratrol or simvastatin, extends life span of genetically heterogeneous mice. J Gerontol A Biol Sci Med Sci 2011, 66(2):191-201.

15. Tettelin H, Nelson KE, Paulsen IT, Eisen JA, Read TD, Peterson S, Heidelberg J, DeBoy RT, Haft DH, Dodson RJ, et al: Complete genome sequence of a virulent isolate of Streptococcus pneumoniae. Science 2001, 293(5529):498-506.

16. Hinojosa E, Boyd AR, Orihuela CJ: Age-associated inflammation and toll-like receptor dysfunction prime the lungs for pneumococcal pneumonia. J Infect Dis 2009, 200(4):546-554.

17. Orihuela CJ, Gao G, Francis KP, Yu J, Tuomanen El: Tissue-specific contributions of pneumococcal virulence factors to pathogenesis. J Infect Dis 2004, 190(9):1661-1669.

18. Methe H, Kim JO, Kofler S, Nabauer M, Weis M: Statins decrease Toll-like receptor 4 expression and downstream signaling in human CD14+ monocytes. Arterioscler Thromb Vasc Biol 2005, 25(7):1439-1445.

19. Shyamsundar M, McKeown ST, O'Kane CM, Craig TR, Brown V, Thickett DR, Matthay MA, Taggart CC, Backman JT, Elborn JS, et al: Simvastatin decreases lipopolysaccharide-induced pulmonary inflammation in healthy volunteers. Am J Respir Crit Care Med 2009, 179(12):1107-1114.

20. Takeuchi S, Kawashima S, Rikitake Y, Ueyama T, Inoue N, Hirata K, Yokoyama M: Cerivastatin suppresses lipopolysaccharide-induced ICAM-1 expression through inhibition of Rho GTPase in BAEC. Biochem Biophys Res Commun 2000, 269(1):97-102.

21. Okouchi M, Okayama N, Omi H, Imaeda K, Shimizu M, Fukutomi T, Itoh M: Cerivastatin ameliorates high insulin-enhanced neutrophil-endothelial cell adhesion and endothelial intercellular adhesion molecule-1 expression by inhibiting mitogen-activated protein kinase activation. J Diabetes Complications 2003, 17(6):380-386.

22. Kimura M, Kurose I, Russell J, Granger DN: Effects of fluvastatin on leukocyte-endothelial cell adhesion in hypercholesterolemic rats. Arterioscler Thromb Vasc Biol 1997, 17(8):1521-1526.

23. Tleyjeh IM, Kashour T, Hakim FA, Zimmerman VA, Erwin PJ, Sutton AJ, Ibrahim T: Statins for the prevention and treatment of infections: a systematic review and meta-analysis. Arch Intern Med 2009, 169(18):1658-1667.

24. Yao HW, Mao LG, Zhu JP: Protective effects of pravastatin in murine lipopolysaccharide-induced acute lung injury. Clin Exp Pharmacol Physiol 2006, 33(9):793-797.

25. Pirat A, Zeyneloglu P, Aldemir D, Yucel M, Ozen O, Candan S, Arslan G: Pretreatment with simvastatin reduces lung injury related to intestinal ischemia-reperfusion in rats. Anesth Analg 2006, 102(1):225-232.

26. Ando H, Takamura T, Ota T, Nagai $Y$, Kobayashi $\mathrm{K}$ : Cerivastatin improves survival of mice with lipopolysaccharide-induced sepsis. J Pharmacol Exp Ther 2000, 294(3):1043-1046.

27. Antunes G, Evans SA, Lordan JL, Frew AJ: Systemic cytokine levels in community-acquired pneumonia and their association with disease severity. Eur Respir J 2002, 20(4):990-995.

28. Muller HC, Hellwig K, Rosseau S, Tschernig T, Schmiedl A, Gutbier B, Schmeck B, Hippenstiel S, Peters H, Morawietz L, et al: Simvastatin attenuates ventilator-induced lung injury in mice. Crit Care 2010, 14(4):R143.

29. Bergman P, Linde C, Putsep K, Pohanka A, Normark S, Henriques-Normark B, Andersson J, Bjorkhem-Bergman L: Studies on the antibacterial effects of statins-in vitro and in vivo. PLoS One 2011, 6(8):e24394.

30. Jerwood S, Cohen J: Unexpected antimicrobial effect of statins. J Antimicrob Chemother 2008, 61(2):362-364

31. Wartha F, Beiter K, Albiger B, Fernebro J, Zychlinsky A, Normark S, Henriques-Normark B: Capsule and D-alanylated lipoteichoic acids protect Streptococcus pneumoniae against neutrophil extracellular traps. Cell Microbiol 2007, 9(5):1162-1171.

32. Beiter K, Wartha F, Albiger B, Normark S, Zychlinsky A, Henriques-Normark B: An endonuclease allows Streptococcus pneumoniae to escape from neutrophil extracellular traps. Curr Biol 2006, 16(4):401-407.

33. Abraham E: Neutrophils and acute lung injury. Crit Care Med 2003, 31(4 Suppl):S195-199.

34. Marks M, Burns T, Abadi M, Seyoum B, Thornton J, Tuomanen E, Pirofski LA: Influence of neutropenia on the course of serotype 8 pneumococcal pneumonia in mice. Infect Immun 2007, 75(4):1586-1597.
35. Lynch JP 3rd: Hospital-acquired pneumonia: risk factors, microbiology, and treatment. Chest 2001, 119(2 Suppl):373S-384S.

doi:10.1186/1471-2180-12-73

Cite this article as: Boyd et al:: Impact of oral simvastatin therapy on acute lung injury in mice during pneumococcal pneumonia. $B M C$ Microbiology 2012 12:73.

\section{Submit your next manuscript to BioMed Central and take full advantage of:}

- Convenient online submission

- Thorough peer review

- No space constraints or color figure charges

- Immediate publication on acceptance

- Inclusion in PubMed, CAS, Scopus and Google Scholar

- Research which is freely available for redistribution 